\title{
The Metaphysics of Sex and Gender
}

\author{
Ásta Kristjana Sveinsdóttir \\ San Francisco State University \\ asta@sfsu.edu
}

\begin{abstract}
In this paper I offer an interpretation of Judith Butler's metaphysics of sex and gender and situate it in the ontological landscape alongside what has long been the received view of sex and gender in the English speaking world, which owes its inspiration to the works of Simone de Beauvoir. I then offer a critique of Butler's view, as interpreted, and subsequently an original account of sex and gender, according to which both are constructed - or conferred, as I would put it - albeit in different ways and subject to different constraints.
\end{abstract}

\section{Introduction ${ }^{1}$}

It has become commonplace in certain academic circles and in popular discourse to insist that the categories we live by, and which shape our lives, are socially constructed. However clichéd it may have become to say that such categories as gender or race are socially constructed, it is often quite hard to know what that claim amounts to and what conclusions can be drawn from it. This is so much the worse because often this claim is seen to support some radical political agenda: although we live by these, often oppressive, categories, we don't have to. Our social life could be organized in ways that are not oppressive.

Judith Butler is perhaps one of the few theorists with a recognizable metaphysical story to support her radical political agenda (Gender Trouble and Bodies that Matter). ${ }^{2}$ In this paper I will examine her account of gender and sex and attempt to situate it within the ontological landscape. In particular, I am interested in distinguishing Butler from Beauvoirean feminist metaphysics and from radical linguistic constructivism. I think Butler offers very important insights into the construction and perpetuation of sex and gender, but that her account has serious problems. I conclude by offering an account of sex and gender according to which both are socially constructed, albeit in different ways and subject to different constraints. In doing so I offer a general framework for making sense of the claim that a particular category is socially constructed, a framework I term a "conferralist" framework.

\section{Judith Butler's Account of Sex and Gender: An Interpretation}

My interpretation of Butler's views centers around four ideas: 
Firstly, Butler offers a reorientation in the way we are to think of the relationship between gender and sex. Sex is now to be thought of as materialized through the regulatory schemes of gender, as opposed to gender being the social significance of sex, as the post-Beauvoirean feminist theory has had it. I appeal to the idea that assertions of sex are normative to try to capture that reorientation. Secondly, I appeal to an analogy with a game to illuminate how the regulatory schemes of gender work to determine meaningfulness. Thirdly, I appeal to Hegel's expressivist theory of the development of the subject and of objectification to cast more light on how sex becomes materialized on Butler's story. Lastly, I appeal to an analogy with Kant's transcendental idealism to help to situate Butler's story in the ontological landscape between the Beauvoirean position and the radical linguistic constructivist one.

\section{A. The Legacy of Simone de Beauvoir}

It is with Simone de Beauvoir's Second Sex ${ }^{3}$ that a distinction between sex and gender begins to be made in feminist theory. ${ }^{4}$ Sex is taken to be a biological category, and gender the cultural interpretation of sex. For Beauvoir and her followers, drawing the sex/gender distinction had liberatory purposes, for the aim was to argue against the view that, to put it rather generally, social reality was determined by natural reality. Division of labor between men and women, and the inequality following from that division, had been thought to have a natural justification in biology: women's biological features explained and justified women's place and function within the social sphere. ${ }^{5}$ Beauvoir's point was precisely that this cannot be done, for the question of the justification for the organization of social reality is a substantive normative question which requires a substantive answer. It is the question of how we ought to organize social reality, which types of organization are justifiable, which not. The biological facts are just facts, brute facts, and no matter what those facts are they do not entail an answer to the normative question. Beauvoir thought that there might even be biological inequality between the sexes (males are larger, women menstruate etc.), but from that nothing should follow about gender inequality. If anything, social organization should make up for biological inequality.

What is Butler's complaint about the Beauvoirean account? First, she points out that feminist scholars have argued that the notion of nature and the relation between nature and culture, which is presupposed by the Beauvoirean account, is quite problematic. It assumes that nature is something passive, acted upon (and controlled) by culture, and does not take into account that, as Butler puts it, "[the concept of] nature has a history, and not merely a social one, but, also, that sex is positioned ambiguously in relation to that concept and its history" (Bodies 5). 
How are we to understand the complaint that the Beauvoirean account misses that the concept of nature has a history? I think that we have to assume that her complaint is that it is not only what is social that is constructed, but that what is natural isn't so untainted as the Beauvoirean assumed. But why should that follow from the fact that the concept of nature has a history?

To say that the concept of nature has a history seems to me to mean any or all of the following:

1. that over time what has counted as natural has changed, i.e., the extension of the concept natural has undergone change;

2. that over time the content of the concept has changed, i.e., the constitutive criteria for being natural have changed; 6

3. that over time people's beliefs about what is natural has changed, i.e., people's association with the concept natural has changed.

How would a commitment to any of the above invite one to say that sexual distinctions were constructed? One line of thought might be to say that if the criterion for being male or female has undergone change, then it follows that what it is to be male or to be female has changed. And if so, how can the male/female distinction help but be constructed? For the assumption is that if the distinction between the sexes is a natural distinction, then it is not changeable? But such an argument won't do, because the Beauvoirean has an easy response. She will say that the criterion for being male or female is merely an epistemic criterion, a way of telling, not a metaphysical criterion constitutive of what it is to be male or female. Our conceptions of, or beliefs about, the natural world are, of course, imperfect, and the many proposed criteria for being male or female belong to those. Butler's opponent may think there is a real, ${ }^{8}$ natural, distinction between male and female, but that our criteria have not yet captured that distinction-have not yet managed to divide nature at its joint. Or she may think that nature has too many joints related to sexual differences and that it is up to us to find criteria to latch on to those joints that are of interest to us. ${ }^{9}$ Either way she goes, it is clear that Butler does not succeed in pointing out a weakness of the Beauvoirean position simply by noting that the concept of nature has a history. Something more is needed. Is something more in the offing? Perhaps. A quote from Gender Trouble gives us a glimpse of what that might be:

It would make no sense, then, to define gender as the cultural interpretation of sex, if sex itself is a gendered category. Gender ought not to be conceived merely as the cultural inscription of meaning on a pregiven sex (a juridical conception); gender must also designate the very apparatus of production whereby the sexes themselves 
are established. As a result, gender is not to culture as sex is to nature; gender is also the discursive/cultural means by which "sexed nature" or "a natural sex" is produced and established as "prediscursive," prior to culture, a politically neutral surface on which culture acts.... How, then, does gender need to be reformulated to encompass the power relations that produce the effect of a prediscursive sex and so conceal that very operation of discursive production? (7)

We are not yet in a position to evaluate the crucial claim that sex itself is a gendered category, pretending, so to speak, to be one uncontaminated by gender or other value. And we won't be in a position to evaluate this claim until we have gotten to know more about Butler's motivations for her view and the reorientation she is suggesting.

So let us consider one possible motivation. One way to distinguish between constructivism (Butlerian or a more radical kind) and a Beauvoirean view is to say that they disagree about where questions of value arise. The constructivist thinks that questions of value go all the way down, that there isn't a base layer, a layer of fact, at which no questions of value arise. Beauvoir can be seen to be committed to such a base layer of biological, natural facts. What do I mean by "questions of value"? I don't mean just questions about right and wrong, or what individuals or communities should do, but mean value more broadly, including cognitive value. A main motivation for a constructivist account is the deep-seated belief that questions of value arise in more places than we are aware of. The constructivist is thus often involved in a debunking effort: to show that certain claims to objectivity are unfounded and social organization based on such claims thus unjustified.

The above suggestions are all rather general. What we need to know here is if Butler is indeed motivated by the belief that questions of value go all the way down, how does that belief get translated into her theoretical proposal? How and where does she locate value, to which the Beauvoirean has been blind? My suggestion is that Butler's claim is that certain assertions, which the Beauvoirean holds to be assertions of fact, are, at least to some degree, normative. Which assertions? Definitely assertions to the effect that someone is of a certain sex; perhaps more assertions. Would Butler want to say that all assertions are to some degree normative? Probably not, but perhaps that a certain class of assertions-let me call them "kind assertions"-are all to some degree normative. What is a kind assertion? It is an assertion to the effect that $S$ is of kind $\mathrm{K}$, e.g., that Jodie Foster is a woman, that Jamie Lee Curtis is female.

The claim that questions of value go all the way down might make one think that Butler's position is a radical linguistic constructivist one: everything is constructed, everything is language, or everything is text. This is not Butler's position. In fact, she 
is eager to distance herself from such a view. Let us examine her arguments against such a position.

\section{B. Butler Distinguished from a Radical Linguistic Constructivist}

The problem Butler points to is a dilemma for the radical linguistic constructivist who attempts to make sense of the Beauvoirean truism that gender is the social significance of sex: either the radical linguistic constructivist shows the limits of her own position, or her view is reduced to linguistic monism (Bodies 5). The radical linguistic constructivist is committed to the view that everything is language, text, or discourse. Let us examine the two horns of this dilemma. On both horns, gender is constructed. The problem is what to do about sex.

If the radical linguistic constructivist says that sex itself is unconstructed, then she has conceded that not everything is constructed. Is she then, after all, committed to a view according to which there are things in the world that are not constructed, something like a base layer of natural facts? But if so, then it is hard to see how she differs from the Beauvoirean (except, of course, that her claims appear more inflammatory).

On the other hand, if the radical linguistic constructivist says that sex is itself a linguistic construction, then she is in no better position than the radical linguistic constructivist who rejects the sex/gender distinction altogether. For both the view is reduced to linguistic monism. That is the unhappy view that everything there is is a linguistic construction. For a feminist, the challenge for linguistic monism is particularly acute: How to make sense of material violence against women, make sense of rape, of economic hardship? ${ }^{10}$ Such violence surely is not a linguistic construction, and the very suggestion that it might be is offensive. For if it were a linguistic construction, would it not follow that by changing our language or our discourses we could stop such violence? The very suggestion seems, on the face of it, even contrary to feminist aims. For what would have been the point of the conscious-raising and the overcoming of our false consciousness, in the beginning of the century for the proletariat, in the seventies for Western women? Did we create social problems by beginning to be able to describe aspects of the world in a different way? Certainly not. Isn't there an important sense in which there was already something harmful happening, and the availability of the description made us able to recognize it? This is an additional problem for the linguistic constructivist caught by the other horn. However, whereas that horn exposed an internal problem to the position, this one (merely) poses an external problem. It is of course a stronger criticism to be able not only to point out that a view doesn't do what one thinks it should aim to do, but also show that the view cannot do what its proponents intend it to do. 
In light of the difficulties that a feminist radical linguistic constructivist faces, it is not surprising that many feminists have thought that feminism needs to assume that sex is unconstructed just like the Beauvoireans do. Butler thinks that it is misguided to think that a feminist theory cannot proceed without presuming the materiality of women's bodies, or in her phrase "the materiality of sex" ("Contigent Foundations" 17). The radical linguistic constructivist position is, to be sure, problematic, as it seems unable to make sense of the material violence women suffer. Butler thinks, however, that the options are not exhausted by presuming materiality or negating it (“Contingent Foundations" 17). What is needed is a rethinking of the sex/gender distinction, but perhaps more importantly, a complete shift in orientation-something of a Kantian "Copernican Revolution".

\section{The Elements of Butler's View}

For Butler, then, the question is no longer: "How is gender constituted as and through a certain interpretation of sex? (a question that leaves matter untheorized), BUT: through what regulatory norms is sex itself materialized?" (Bodies 10).

If sexual categories are not joints of nature, what are they then, and why did we ever think they were joints of nature? Butler's suggestion is that sexual categories are regulatory ideals (Bodies 1). This term is borrowed from Foucault, but has its roots in Kant. What is a regulatory ideal? It is a prescriptive norm projected or posited by subjects, as opposed to, say, read off of nature, so to speak. An ideally rational agent is such a norm, for instance: it is an ideal because no actual person is an ideally rational agent, and it is regulatory because there is a demand on all of us that we strive to be such (although we never will be). Butler's suggestion is that the categories of male and female are such ideals, although I believe she thinks that the demand on us that we strive for one of those ideals ${ }^{11}$ is not grounded in the same way as the demand that we strive for rational agency. For part of her aim is a debunking one: to show that this demand on us is a demand to the effect that we help perpetuate the current power structure and that the force of that demand does not come from its being a justified demand, but merely from its being a demand backed with power (Bodies $35) .12$

Coupled with the claim that the category of sex is a regulatory ideal comes a story of what is involved in asserting that someone is of a certain sex. In the case of the Beauvoireans, saying that $S$ is female amounts to asserting a fact, describing what (a part of) the world is like. Not so for Butler. Perhaps we can hold on to the idea that something is being asserted on her view, but only if we allow for a certain ambiguity in the word "assertion", for a descriptive and a prescriptive sense of that word. To assert in the prescriptive sense that $S$ is female is to perform a certain speech act, which 
is expressive of the commitment-one's own or that of the community-that $\mathrm{S}$ be female and be regarded as female ("Contingent Foundations" 17). ${ }^{13}$

An analogy may be helpful here. Consider a game called the "gender game". The game involves a host of complicated rules for behavior within the game. There are only two types of role a player can play-either one enters the game as a girl or as a boy-and with time one advances to different stages of that role (the man or the woman stage), giving one different duties and responsibilities and different possible moves.

Now, there has been no mention of sex yet. What would be the role of sex in my hypothetical gender game? If my analogy is to work, then there has to be place for sex within the gender game. I suggest that in the gender game the categories of sex are projected regulatory ideals, ideals that best fit the perpetuation of the game. In fact they are gendered ideals, i.e., shaped by gender rules that regulate what bodies and body parts have meaning within the game. How exactly? I would like to attempt to link it to Butler's idea that "'to matter' means at once 'to materialize' and 'to mean"'(Bodies 32). I take this to mean that in this context the bodies that matter in the gender game are those that are materialized in accordance with the rules of the game; they are the intelligible bodies. It is then the matrix of intelligibility-in other words the rules of the gender game-that governs the materialization of the bodies that come to matter to the game. Let us take Butler's own example:

Consider the medical interpellation which (the recent emergence of the sonogram notwithstanding) shifts an infant from an "it" to a "she" or a "he," and in that naming, the girl is "girled," brought into the domain of language and kinship through the interpellation of gender. But that "girling" of the girl does not end there; on the contrary, that founding interpellation is reiterated by various authorities and throughout various intervals of time to reenforce or contest this naturalized effect. The naming is at once the setting of a boundary, and also the repeated inculcation of a norm. (Bodies 7 )

Before the baby is girled it is not yet part of the gender game; it does not fit into the scheme of things, is not part of the symbolic domain--it does not yet matter. What there is before the naming is unintelligible (in the game) and it is only through being articulated as a girl that the girl comes into being as a participant in the game. ${ }^{14}$

What might the mechanism, by which sex gets materialized, be? Here Butler's Foucauldean story has decidedly Hegelian elements. Let me describe the Hegelian expressivist account of the development of the subject, and of objectification. I will then suggest that these two models are the mechanism by which sex gets materialized, gendered, and rendered intelligible, on Butler's story. 
The Hegelian expressivist idea is roughly as follows: A subject forms a conception or model of itself and its relation to the world, followed by the acting out or actualization of this conception. To "act out" a conception is, roughly speaking, to behave as if that conception were true and strive to make it apply, make it true, "perform" that identity. How so? With a conception are associated norms for behavior and to act out a particular conception is to take those norms as binding on oneself and to strive to act in accordance with them.

The other side of the coin is the story of objectification, which goes as follows: The self or subject forms a conception of the object and attempts to actualize that conception. This the self does by acting as if the object conforms to the conception the self has of it. This is thus third-party identification, followed by an attempt to make that identification apply. The objectification succeeds if the object does not, or is not able to, resist the conception offered of it by the subject. In perhaps the most interesting case the object is itself a subject, a self. In that case, it may react to the objectification in either of two ways: i) take on the conception imposed on it and attempt to actualize that conception; ii) fight the objectification and the conception imposed and attempt to (re)claim control over its self-conception.

Let me draw these elements together a bit more and address how they work together in a social setting. Let's think about these conceptions a subject may adopt as a conception of itself. In a particular social or cultural context there are several such conceptions that may be available to a subject to adopt as its own, but, importantly, the subject's choice is constrained by the available conceptions. We can think of them as conceptions of what it is to be a member of some social kind and the associated norms of behavior for members of that kind. Only conceptions that appear to fit us "well enough" are available for our adoption, and often certain socially salient conceptions are thrust upon us and we must negotiate other people's acting as if that is our conception. For instance, the conception of what it is to be a woman is not only available to me but thrust upon me every day, and I embrace it more or less and act out that conception every day: I act as if it is true, and the more I act as if it is true, the more accurately it fits me. This is so, even if I negotiate what comes with adopting that conception to some extent. Some of the norms of behavior associated with being a woman I embrace fully and take as binding on me; others I try to resist. Sometimes this resistance is without any repercussions, sometimes it results in social sanctions of some kind.

Both sides of the Hegelian coin work together to form the subjects within the gender game and to perpetuate the gender game itself. The first experience a player in the gender game has of the game is of being handed a conception that he or she is to act out. She or he is, in a sense, treated as an object. Then, the better the player acts out 
the conception offered, the better she or he does in the game. The objectification has likewise worked to the same degree, since she or he has taken over the conception offered and started to act out that conception.

How does the discussion of the two Hegelian models help understand the process of materialization of sex within the gender game? Let us think about what bodies and body parts come to have meaning within the game. They are the bodies and body parts that do not resist the conception imposed on them. The available conceptions are all ones that fit the perpetuation of the gender game itself. What sex is, is whatever conforms to the gendered ideals. The subjects' conceptions of themselves as embodied beings, and the conceptions of their own bodies and the significance of each body part, even what counts as a body part, are all shaped by the gender rules, the matrix of gender. And it is even part of the gender game that sex be thought of as not contaminated by the gendering, but as a natural category. Such naturalization of sex is a necessary part of the perpetuation of the gender game itself. ${ }^{5}$ How so? Treating sex distinctions as natural makes them seem inevitable as well as the source of gender distinctions and hierarchies in a way that legitimates them and thereby the gender game itself. Naturalizing sex is thus an important part of the ideology that helps perpetuate the gender game.

\section{Butler's Proposal: Life is a Gender Game}

I take it that Butler's proposal is that a game like the gender game is what we live in. ${ }^{16}$ I now want to explore the significance of that claim for the question of what kind of metaphysics Butler is offering.

For one thing, Butler has suggested a reorientation: our assertions do not fit the world, but the world fits our assertions. It is the Kantian suggestion that we shape our world more than we have hitherto realized. But the Kantian inheritance does not end with that. For the structure of the domain of the gender game and its relation to what is outside the game can be explained by analogy to Kant's transcendental idealism.

The analogy works as follows: the realm of the gender game is like Kant's phenomenal realm. It is the realm of spatio-temporality (materiality) and intelligibility. There is another realm, but what resides there can only be thought, ${ }^{17}$ but the thought about those objects is not contentful. For Kant the phenomenal realm is the realm of objects as they are for us, as they are subject to the conditions of possible experience. The noumenal realm on the other hand is the realm of objects as they are independent of those conditions. The Butlerian symbolic domain is the domain of signifiability and intelligibility (Bodies 138). The objects we experience there are objects as they 
are subject to the conditions of the gender game, the gender matrix. We can think of objects as they are independent of those conditions, but in certain cases such thoughts will not be very contentful, because gender influences the way such objects appear to us so completely. The suggestion is that sex is such an object, and that we cannot think about sex or sexualized objects contentfully or experience them independent of the conditions of gender. But does this mean that we are stuck with the current gendering of sex? Not at all. I think Butler might say that although we may not be able to think or experience sex independently of the conditions of gender, the actual conditions of gender need not be the conditions that sex is subject to. But then what is needed for change is, in the first instance, a critical examination of our actual gender norms.

The Kantian analogy breaks down when one points to objects that can be thought about or experienced contentfully without being subject to the conditions of the gender game. But that's alright. Butler can allow that the gender game not be the only game in town, and that in fact the gender game interact with other games, some of which can be just as oppressive as the gender game. ${ }^{18}$ However, I think the Kantian analogy helps us to situate Butler's position in the ontological landscape in between Beauvoir and the radical linguistic constructivist. Let us recall what the relationship is between sex and gender on Butler's story. Instead of sex being a natural category, and gender the social significance of sex, sex is really a gendered category posited by us and claimed to be a natural one so that it can better help perpetuate the gender game. Gender categories, on the other hand, are roles or ideals constitutive of the gender game itself. How does Butler's ontological picture then compare to the Beauvoirean one? Contrary to the Beauvoirean she thinks that all sex is constructed or materialized through the matrix of gender. After her shift in orientation, Butler's point that the concept of nature has a history appears stronger, since she is able to resist the Beauvoirean move that the criteria we are talking about are purely epistemic ones. Butler will insist that the criteria for sex distinctions are indeed constitutive criteria of what it is to be male or female. However, the significance of being male or female is tied up with what meaning it has within the gender game.

Although sex is constructed on Butler's view, her position does not collapse into linguistic monism with the radical linguistic constructivist. For she is not interested in the claim that there isn't anything before the materialization in accordance with the matrix of gender. The point is rather that what meaning and significance sex and sexualized body parts have, they have such meaning and significance in virtue of being given to us as gendered, for it is the gender matrix that is the matrix of intelligibility for sexed objects. 


\section{E. Critique}

My interpretation of Butler's constructivism has centered around four ideas. Let me tie them more tightly together. First, I suggested that Butler is not merely advocating a rethinking of the sex/gender distinction, but a complete shift in orientation. This is a Kantian "Copernican Revolution" of sorts: the picture is not that our thought and practices conform to how the world is, but that, at least sometimes, the world conforms to our thought and practices. I appealed to a rethinking of what is going on when it is asserted that someone is of a certain sex, and suggested that instead of thinking of that assertion as a mere assertion of fact-of how the world is-that we think of it as, at least to some degree, normative. The suggestion, then, is that assertions that someone is of a certain sex, and that some body parts and acts are sexualized, are such normative assertions and that our thought and practices partake in making them true. I then appealed to the analogy with a gender game to attempt to explain how bodies and body parts acquire meaning within our thought and practices. Such acquisition of meaning holds hands with the materialization of the body and body parts within the game. The actual mechanism of materialization I then tried to explain by reference to Hegel's expressivist model of the development of the subject and his model of objectification. Finally, I attempted to explain the relationship between the conditions of intelligibility within the gender game, and that which is outside the game by reference to Kant's distinction between the phenomenal and the noumenal realms. That analogy is also supposed to help us see how Butler's ontology differs from the Beauvoirean one and that of the radical linguistic constructivist.

If Butler is right, and it is not only that the category of sex is gendered, but that the naturalization of it is a necessary part of the perpetuation of the gender hierarchy, then it is not only that she can resist the Beauvoirean position, but she poses a positive challenge to the Beauvoirean feminist: Is the construction of the category of female as a coherent and stable subject an unwitting regulation and reification of gender relations (Gender Trouble 5)? And is not such a reification precisely contrary to feminist aims? To what extent does the category of female achieve stability and coherence only in the context of the gendered matrix?

I'm inclined to think that the critique Butler offers of the Beauvoirean position is right on target and the claim that sex gets materialized in accordance with the matrix of gender is both illuminating and accurate. The worry I have is what happens to the biologically given on this picture: out of what does sex get materialized? How come some people are better able to pass as male or female than other people? Doesn't that have something to do with certain biological features that are simply given and no 
amount of interpretation can have disappear? Isn't it the case that only people with certain functioning body parts can bear offspring with people with certain other functioning body parts? Butler's account does not seem to be able to explain that. In fact her account seems open to the charge that in principle any body part could be a sexed body part and that there is no biological (as opposed to social) reason why some body parts have sexual significance and not others. I think we are in need of an account of the construction of sex that takes seriously the gendered societal influences on that process, but that also gives the constraints of nature its due. I now want to suggest such an account.

\section{Conferralism about Sex and Gender}

Given the worries raised about Butler's account, I want to suggest another way to account for the sex/gender distinction. On this account, both sex and gender are constructed —or as I would put it, conferred-but in different ways, and subject to different constraints. Let me start by explaining the key notion, that of a conferred property.

Recall the disagreement between Socrates and Euthyphro over whether an action was pious because it was loved by the gods or whether the gods loved the action because it was pious (Plato 10a). That disagreement concerns whether the gods' love confers the property of being pious on the action or whether being pious is a property the action has independently of the gods and their affections such that upon detecting the property the gods come to love the action. Euthyphro initially holds a conferralism about the property of being pious; he thinks the gods' love confers the property of being pious on the action.

This disagreement between Euthyphro and Socrates is a disagreement about the metaphysical status of the property of being pious: What kind of property is it? How independent is the property from the attitudes and practices of the gods? How real is it?

In my view, the debate over the social construction of gender, sex, and other categories exactly mirrors the debate between Euthyphro and Socrates: What kind of property is the property of being a woman or being female? How independent are these properties from human thoughts, attitudes, and practices? How natural or real are they? The Euthyphronic position is that they are not naturally given or real, but rather dependent in some way on human thoughts, attitudes, and practices. But how?

The idea of a conferred property can help us clarify different views on the status of gender and sex. Once I have clarified what a conferralism about a property is, I hope the reader will agree with me that any theorist who thinks gender (or sex) is socially 
constructed, when that is meant as a metaphysical thesis, is a conferralist about the property of being a woman (or female). The difference among the various social constructionist accounts will then amount to differences in the details of the conferralism they are committed to.

I hope the intuitive distinction between a conferred property and a non-conferred property is clear. I will make precise what giving a conferral account of a property amounts to shortly but let us first linger with the range of conferred properties. Lots of properties are obviously conferred. Consider, for example, the property of being hip or cool. Isn't it natural to think that being hip or cool is conferred on people by members of some in-group? It doesn't seem plausible to say that someone is hip or cool irrespective of the attitudes of the members of that in-group.

Some properties are plausibly conferred, but bear a close relationship to some nonconferred properties. Consider, for instance, some baseball properties, such as a pitch's being a ball or a strike. There is a physical property, presumably nonconferred, of having traveled some trajectory $\mathrm{T}$ from the fingers of the pitcher to the glove of the catcher. But whether a pitch is a strike or a ball is not a matter of what that trajectory $\mathrm{T}$ is - it is a matter of what the umpire judges that trajectory to be. The umpire is attempting to track what the physical property $\mathrm{T}$ is, but it is his judgment as to what $\mathrm{T}$ is that makes something a ball or a strike. The properties of being a ball or a strike are thus conferred by his judgement.

When one offers a conferral account of a property there are five components that need to be specified: ${ }^{19}$

Property : what property is conferred, e.g. being pious, being hip, being a strike

Who : who the subjects are, e.g., the Greek gods or the baseball umpire

What : what attitude, state, or action of the subjects matter, e.g., the gods' love or the umpire's judgement

When : under what conditions the conferral takes place, e.g., normal, ideal, or some specified conditions. This can be a one-time conferral or, which is perhaps more common, an iterative phenomenon stretching over a long period of time.

Tracking : what the subjects are attempting to track (consciously or not), if anything

\section{A. Conferralism about Gender}

It is now easy to see how various constructivist accounts of gender can be brought under the hat of conferralism. Most would probably agree that gender is conferred by subjects or groups of subjects (even "society"), but they will disagree on what about the subjects does the conferring, under what conditions the conferral takes place, and 
what, if anything, the conferral is supposed to track: is it attempting to track sex assignment, role in biological reproduction, sexual roles, or merely role in the organization of society, irrespective of assumed sex?

Take the Beauvoirean view. ${ }^{20}$ On a plausible interpretation of this view sex is a nonconferred biological property, but gender is conferred by society on people taken to be of a certain sex. With the conferral of gender come duties, privileges, and burdens. Gender assignment, on this view, is supposed to track sex assignment, which is assumed to be biologically given, but gender properties are social properties.

Plausibly there has been a persistent assumption in the background ${ }^{21}$ that in tracking one of these things, i.e., sex assignment, role in biological reproduction, sexual role, role in societal organization, etc., we manage to track the other phenomena as well. We can then understand various kinds of subsequent feminist and queer theoretical work and activism as challenging that assumption: these categories are not coextensive and tracking one of these properties need not help us track the others.

My suggestions as to how gender is conferred makes gender out to be highly contextdependent. Not only is it deeply context-dependent when it comes to historical periods and geographic locations, but the same geographical location and time period can allow for radically different contexts, so that a person may count as a woman (or man or what have you) in some contexts and not others. This is because different properties are being tracked in different contexts: in some contexts it is perceived role in biological reproduction, ${ }^{22}$ others it is role in societal organization of various kinds, sexual engagement, presentation of the body, in the preparation of food at family gatherings, ${ }^{23}$ etc.

There may be contexts that are such that to count as a woman (or of some other gender) in them, one need not only be perceived to have some central property being tracked in that context, such as perceived role in biological reproduction, but also not be seen to trouble the assumption that one have the other properties traditionally associated with that gender (societal role, gender-appropriate presentation, sexual orientation, and the like) as well. ${ }^{24}$ Thus, there are contexts where there may be people who do not count as being of any of the available genders. Such contexts can vary in the attitudes towards those who are perceived not to fit the available genders. In certain contexts people who don't fit may be hailed as special, even sacred, creatures; in other contexts they can suffer abuse that threatens their lives and limbs. New contexts are coming into being every day as assumptions are questioned. Thankfully, although many of these assumptions and expectations are very hard to change, they are not set in stone. Here is thus the general schema: 
Property : being of gender G, e.g., a woman, man, trans

Who : the subjects $S$ in the particular context $C$

What: the perception of the subjects $S$ that the person have the grounding property $\mathrm{P}$

When : in context $\mathrm{C}$

Tracking : the grounding property $\mathrm{P}$

Unlike in the baseball case, the conferral is not a one-time act, but rather involves a standing attitude, namely the perception by the subjects in the context that the person have the relevant grounding property. This perception can be in error and the person may in fact not have the property in question.

In certain contexts, being transgender will count as a separate gender; in others, it will simply raise trouble for the gendering structure of that context and disrupt the expectations of the coextension of the associated gender properties. In certain contexts, being perceived as being of a certain sex may be an essential grounding property; in other contexts, it may be highly irrelevant.

Thus there are several things that may happen in a particular context: a person can resist the conferral of the property (the gender assignment), but how successful such resistance can be will vary. Certain contexts may be particularly "silencing" in this regard, such that attempts to trouble one's gender assignment receive no uptake and remain futile. This is analogous to what can happen in linguistic contexts where it can be impossible to say certain things. Try one may, but the context may prevent one from being heard and understood as saying what one intends to say. ${ }^{25}$ Similarly, one may try to trouble people's perception of oneself in a particular context, but there may be no other gender assignment available. Some contexts are even such that there is no possibility of simply not fitting into one of the available genders. Just as in some linguistic contexts it may be impossible to say what one wants to say, so there can be some action contexts where it is impossible to perform the actions one wants to perform, because the performance of the action depends on one's being taken to perform it (or less strictly, taken to have certain properties).

On this account of gender there is thus no one context-independent property of being of a certain gender, e.g., a woman. Instead what we have is a family of contextdependent conferred properties some of which share some grounding properties. Let me now turn to the account of sex.

\section{B. Conferralism about Sex}

The conferralist paradigm can help us makes sense of the value-ladenness of a property or category, without rejecting that there is anything prior to the conferral. It can 
thus help us makes sense of the appearance that a certain property is biologically given, even if it is not. Sex, I believe, is such a property. Being of a certain sex is a conferred property. In fact, it is first and foremost a social (in fact legal) property.

Do I have an argument for that? Here is a first stab: If a property chiefly figures in explanations of social facts, and not natural facts, that suggests that the property is a social property, and not a natural property. Consider, e.g., the natural facts about what kind of human bodies can create offspring together. It is not your sex assignment that allows you to bear or seed children. In fact, there are people whose sex assignment is in no way in dispute who cannot bear or seed children. What allows one to bear or seed children are rather some other properties that the sex assignment is intended to track. Since being of a certain sex is not an explanatory property when it comes to bearing or seeding of offspring, but it is explanatory when it comes to the distribution of various social resources, privileges and burdens, doesn't that suggest that sex is a social property and not a natural one?

Here is thus my methodological suggestion: one should consider in what kinds of explanations the property occurs. If it functions in explanations of various social facts and it isn't playing the explanatory role of various physical or natural facts, but rather some "nearby" property is doing so, that should give us reason to think that the property in question is a social property, and hence conferred.

The second step in offering a conferral account of a property such as being of a certain sex is to tell a plausible story of how the mechanisms of conferral actually work. This is where social metaphysics has to rely on the empirical to offer a plausible story of the nature of the social phenomenon in question. In my story of the mechanism of conferral I turn to the work of Anne Fausto-Sterling and, again, Butler.

In her work (Sexing the Body, "The Five Sexes") the biologist Fausto-Sterling has discussed how unfounded the assumption is that biologically people can be divided neatly into two sexes, female and male, with the associated chromosomes, functioning genitalia, and hormonal levels. She estimates that about 1.7 percent of the general population does not fall neatly into one of these two categories. There is a variety of ways in which one can be intersex: one can have any one of a number of combinations of functioning and non-functioning male and female genitalia; one can have different chromosomes (X, XXY or XYY); or different hormonal levels. Interestingly, a deviation from the statistical norm when it comes to one of these factors (functioning genitalia, chromosomes, hormonal levels) does not line up neatly with deviation from the norm when it comes to one of the other factors. The three ways of dividing people up into sexes not only do not carve nature at some joint where you have fe- 
male on one side and male on the other; these three methods of carving serve up different slices of nature.

But "carving" is not only to be used metaphorically in this context. Even before voluntary sex change operations, newborns with ambiguous sex characteristics have been subject to the scalpel (Sexing the Body).

For this reason I want to give an account of the property of being of a certain sex as a conferred property where the aim is to track certain physical properties, but where the resulting property is a social property, in fact a legal one: ${ }^{26}$

Property : being female, male

Who: Legal authorities, drawing on the expert opinion of doctors, other medical personnel, and parents

What : The recording of a sex in official documents, on the basis of the testimony of parents, doctors, and others. The judgment of the doctors (and others) as what sex role might be most fitting, given the biological characteristics

When : at birth (in the case of newborns); after surgery and hormonal treatment (in the case of older individuals)

Tracking: the aim is to track as many sex-stereotypical characteristics as possible, and doctors perform surgery in cases where that might help bring the physical characteristics more in line with the stereotype of male and female

Unlike in the case of gender, the conferring of sex is a one-time act by relevant authorities, and not subjects in some social contexts. Such subjects can in fact be in error as to what a person's sex assignment is, but a person's perceived sex assignment plays no role in determining that assignment, although it may play a role in determining the person's gender assignment in some context. In this way, some of the Beauvoirean insight is preserved. For there are some contexts where at least one of the things being tracked is sex assignment. In such a context, being of a certain gender is conferred by the perception that the person has a certain sex assignment.

In giving this account of how sex gets conferred, I draw on Butler's work, as interpreted above, as well as Fausto-Sterling's work. The Butlerian elements should be clear: Sex assignment is guided by the aim to have the individual in question exhibit as many sex-stereotypical properties as possible, with the aid of medical treatment, if necessary. It isn't quite that the gender matrix dictates the materialization of sex, as Butler would have it, but that sex-stereotypes, shaped by societal expectations about gender roles and possible ways of being within a society, guides sex assignment. On this account, it isn't the case, as on Butler's, that there are no natural constraints on the materialization of sex, as determined by the gender matrix, for people have vari- 
ous physical properties. But the determination of which physical properties are important for sex assignment, and in particular the assignment of people into one of two sexes, is shaped by societal values and interests.

\section{Conclusion}

Most of the elements of Butler's account are compatible with the conferralism of gender and sex offered here. The only element rejected is the echo of Kant's transcendental idealism in the sense that I want to allow there to be properties that are biologically given and that put constraints on what sex assignment is possible. I don't reject the question as to what there is prior to the conferral of sex, as Butler should, if my interpretation of her is correct. In that way, I am able to benefit from her insight into how the gender matrix shapes sex and sexed bodies, yet leave room for constraints on that shaping on the part of nature.

${ }^{1}$ Acknowledgements: Thanks are due to the following colleagues and friends for comments on earlier drafts of parts of this paper or conversations about it; of course, none of them is responsible for the views expressed herein or any errors of judgement or interpretation: Jennifer Church, Jeanna Eichenbaum, Sally Haslanger, Kattis Honkanen, Jennifer Hudin, Ada Jaarsma, Colin Koopman, Francesca Lattanzi, Jamie Lindsay, Helen Longino, Fiona Macpherson, Ishani Maitra, Rebecca McLennan, Uma Narayan, Jeffrey Paris, Elizabeth Potter, Dennis Rothermel, John Searle, Alice Sowaal, Jacqueline Taylor, Brian Thomas, Shelley Wilcox, Tiffany Willoughby-Herard, Charlotte Witt, Sigríður Porgeirsdóttir, and my students in my classes on Social Ontology and Metaphysics at San Francisco State University.

${ }^{2}$ Whether or not Butler herself considers herself to be doing metaphysics is not the issue. Theorists can have a metaphysics even if they don't consider themselves to be doing metaphysics. Thanks to Helen Longino for this point.

${ }^{3}$ In the French Le Deuxième Sexe (Paris: Librairie Gallimard, 1949).

${ }^{4}$ She did not coin terms for the categories of sex and gender, but by insisting that one is not born, but rather becomes, a woman, she can be read as implicitly drawing such a distinction.

${ }^{5}$ I take the social sphere here to have political, economic, legal, cultural, and religious dimensions.

${ }^{6}$ This might raise a worry about on what grounds we consider this the same concept, but let us leave that aside for now.

${ }^{7}$ Modulo evolutionary changes, taking place over a long long time.

8 I.e., independent of our thought and practices.

${ }^{9}$ One might think that this is a weak kind of constructivism, but the key point is that the proponent of this view is committed to there actually being some joints of nature. Butler seems not committed to that. Nor does she seem to deny that, perhaps because she thinks that making claims about how the world is independent of us is not justified. 
${ }^{10}$ See also "Contingent Foundations" 17.

${ }^{11}$ This is not to say that we can choose which ideal we strive for.

12 See also Gender Trouble 6-7: "The radical splitting of the gendered subject poses yet another set of problems. Can we refer to a "given" sex or a "given" gender without first inquiring into how sex and/or gender is given, through what means? And what is "sex" anyway? Is it natural, anatomical, chromosomal, or hormonal, and how is a feminist critic to assess the scientific discourses which purport to establish such "fact" for us? Does sex have a history? Does each sex have a different history, or histories? Is there a history of how the duality of sex was established, a genealogy that might expose the binary options as a variable construction? Are the ostensibly natural facts of sex discursively produced by various scientific discourses in the service of the political and social interests [false taxonomies? ]? If the immutable character of sex is contested, perhaps this construct called "sex" is as culturally constructed as gender; indeed, perhaps it was always already gender, with the consequence that the distinction between sex and gender turns out to be no distinction at all."

${ }^{13}$ Cf. Gender Trouble 17: “...the question here will be: To what extent do regulatory practices of gender formation and division constitute identity, the internal coherence of the subject, indeed, the selfidentical status of the person? To what extent is "identity" a normative ideal rather than a descriptive feature of experience? And how do the regulatory practices that govern gender also govern culturally intelligible notions of identity? In other words, the "coherence" and "continuity" of "the person" are not logical or analytical features of personhood, but, rather, socially instituted and maintained norms of intelligibility. Inasmuch as "identity" is assured through the stabilizing concepts of sex, gender, and sexuality, the very notion of "the person" is called into question by the cultural emergence of those "incoherent" or "discontinuous" gendered beings who appear to be persons but who fail to conform to the gendered norms of cultural intelligibility by which persons are defined."

${ }^{14}$ Cf. Gender Trouble 8: "Bodies cannot be said to have a signifiable existence prior to the mark of their gender; the question then emerges: To what extent does the body come into being in and through the mark(s) of gender? How do we reconceive the body no longer as a passive medium or instrument awaiting the enlivening capacity of a distinctly immaterial will?"

${ }^{15}$ Cf. Gender Trouble 33: "To expose the contingent acts that create the appearance of a naturalistic necessity, a move which has been part of cultural critique at least since Marx, is a task that now takes on the added burden of showing how the very notion of the subject, intelligible only through its appearance as gendered, admits of possibilities that have been forcibly foreclosed by the various reifications of gender that have constituted its contingent ontologies."

${ }^{16}$ Cf. Gender Trouble 16: "It would be wrong to think that the discussion of "identity" ought to proceed prior to a discussion of gender identity for the simple reason that "persons" only become intelligible through becoming gendered in conformity with recognizable standards of gender intelligibility."

${ }^{17}$ Cf. Bodies 8: "Paradoxically, the inquiry into the kinds of erasures and exclusions by which the construction of the subject operates is no longer constructivism, but neither is it essentialism. For there is an "outside" to what is constructed by discourse, but this is not an absolute "outside," an ontological thereness that exceeds or counters the boundaries of discourse; as a constitutive "outside, "it is that which can only be thought-when it can-in relation to that discourse, at and as its most tenuous borders."

${ }^{18}$ For example the race game, the class game, the ethnic game. 
${ }^{19}$ Here I draw on my "Essentiality Conferred". In that work I did not include Tracking as an integral aspect of the account, but now think it helpful.

${ }^{20}$ Again, this may not be Beauvoir's own view, but rather that of feminists influenced by her for whom sex is a biological category and gender the social interpretation of sex.

${ }^{21}$ My aim is not to settle that question here.

22 Sally Haslanger prioritizes this for the purposes of her analysis. Cf. e.g., "Gender and Race".

${ }^{23}$ It is easy to think of anecdotes that fit the various context descriptions. My friend, Agustín Rayo, told me a nice story of going with his mother, Julieta Fierro, a famous astronomer and public figure, to a genderly rigid gathering of extended family in Mexico. Apparently the expectations were such that the women would get together early in the morning on Sundays to start cooking the meal, and the men would gather and drink beer and chat. Later the men would be seated at the table and the women would wait on them while they ate. Only after the men were done eating would the women eat the leftovers. While Agustín's mother was a bad fit in each company, she ended up sitting and eating with the men. There was never a repeat of that family experiment. The way I analyze this example is that it is not that Julieta Fierro counted as a woman or a man in that context. This was precisely the kind of context where there was no gender available to her. She was treated as an other. While she ended up conversing and eating with the men, the fact that she ceased to partake in such family gatherings suggests that there was not a comfortable "third gender" category available in the context.

24 This is why in some contexts lesbians don't quite count as women, and that in some contexts butch lesbians are more challenging than femmes as they very obviously trouble the assumption that all of the gender-stereotypical properties inhere in the same person.

${ }^{25}$ Consider, e.g., being an actor on stage and attempting to warn a theater audience that there is a fire in the theater by shouting "fire!", where the audience continues to laugh. See Ishani Maitra's "Silencing Speech" and "Silence and Responsibility".

${ }^{26}$ In giving this account of the conferral of sex, I want to leave it open that the sex categories may change in the future. In fact, perhaps the intersex movement has precisely started to trouble the idea that the legal category of sex is the most helpful societal category tracking sex-stereotypical properties. 


\section{Works Cited}

Beauvoir, Simone de. Le Deuxième Sexe. Paris: Librairie Gallimard, 1949; The Second Sex. Trans. and ed. H. M. Parshley. New York: Alfred A. Knopf, 1953.

Butler, Judith. Gender Trouble: Feminism and the Subversion of Identity. New York and London: Routledge, 1990.

---. "Contingent Foundations." Feminists Theorize the Political. Ed. Judith Butler and Joan W. Scott. New York and London: Routledge, 1992.

---. Bodies that Matter. New York and London: Routledge, 1993.

Fausto-Sterling, Anne. Sexing the Body. New York: Basic Books, 2000.

---. “The Five Sexes, Revisited.” The Sciences, July/August 2000.

Haslanger, Sally. "Gender and Race: (What) Are They? (What) Do We Want Them To Be?" Noûs 34:1 (March 2000): 31-55.

Maitra, Ishani. "Silencing Speech.” Canadian Journal of Philosophy (forthcoming).

--- "Silence and Responsibility." Philosophical Perspectives 18 (1):189-208.

Plato. Euthyphro. Geneva: Henri Estienne [Stephanus], 1578. Standard ed. 10a.

Sveinsdóttir, Ásta. "Essentiality Conferred." Philosophical Studies 140.1 (July 2008): $135-148$. 